Tropical Journal of Pharmaceutical Research July 2019; 18 (7): 1461-1466

ISSN: $1596-5996$ (print); 1596-9827 (electronic)

(C) Pharmacotherapy Group, Faculty of Pharmacy, University of Benin, Benin City, 300001 Nigeria.

\title{
Bexarotene enhances heart structure and function in diabetic rats by inhibiting ventricular remodeling and cardiomyocyte apoptosis
}

\author{
Ying $\mathrm{Ma}^{1,2}$, Yunfeng $\mathrm{Li}^{2}$, Yongqiang Ren ${ }^{3}, \mathrm{Xi}_{\mathrm{Guo}}{ }^{2 \star}$ \\ ${ }^{1}$ Medical College of Qingdao University, ${ }^{3}$ Department of Endocrinology, Qingdao Municipal Hospital, ${ }^{2}$ Department of \\ Cardiology, Qingdao Municipal Hospital, Qingdao City, Shandong Province, China
}

*For correspondence: Email: cfui3x@163.com

Sent for review: 9 March 2019

Revised accepted: 28 June 2019

\begin{abstract}
Purpose: To investigate the influence of bexarotene (Bex) on cardiac structure and function in streptozotocin (STZ)-induced diabetes mellitus (DM) rats, and the mechanism of action involved. Methods: Four groups of Sprague Dawley rats $(n=40)$ were used: normal control, DM, DM+ Bex (10 $\mathrm{mg} / \mathrm{kg} / \mathrm{day})$, and $\mathrm{DM}+$ Bex $(20 \mathrm{mg} / \mathrm{kg} / \mathrm{day})(n=10)$. The $D M$ rat model was established by intraperitoneal injection of STZ. Cardiac structure and function of rats were determined and compared. Whole heart and left ventricle were weighed. The protein expressions of Bcl2 and Bax in rat myocardial tissue were determined using Western blotting.

Results: Compared to control group, there was significant reduction in the levels of IVSd (inlet ventricular septal defect) and LVPWd (left ventricle posterior wall in diastole) in DM group, but significant increase in these parameters in DM +Bex $(20 \mathrm{mg} / \mathrm{kg} /$ day) group, relative to $D M$-treated rats $(p<0.05)$. Moreover, there were higher expression levels of Bcl2 and Bax in DM group, when compared with normal control, but Bcl2/Bax ratio was significantly lower $(p<0.05)$. Furthermore, Bcl2 and Bax levels in $D M+B e x(20 \mathrm{mg} / \mathrm{kg} /$ day) group were significantly lower than those in DM group, while $B c / 2 /$ Bax ratio increased significantly $(p<0.05)$.

Conclusion: Bexarotene improves the cardiac structure of DM rats by lowering blood glucose, and by inhibiting ventricular remodeling and cardiomyocyte apoptosis. These findings may be beneficial in the development of new anti-DM drugs.
\end{abstract}

Keywords: Bexarotene, Myocardial remodeling, Cardiomyocyte apoptosis, Streptozotocin, Diabetes, Cardiac structure, Cardiac function

\begin{abstract}
This is an Open Access article that uses a fund-ing model which does not charge readers or their institutions for access and distributed under the terms of the Creative Commons Attribution License (http://creativecommons.org/licenses/by/4.0) and the Budapest Open Access Initiative (http://www.budapestopenaccessinitiative.org/read), which permit unrestricted use, distribution, and reproduction in any medium, provided the original work is properly credited.

Tropical Journal of Pharmaceutical Research is indexed by Science Citation Index (SciSearch), Scopus, International Pharmaceutical Abstract, Chemical Abstracts, Embase, Index Copernicus, EBSCO, African Index Medicus, JournalSeek, Journal Citation Reports/Science Edition, Directory of Open Access Journals (DOAJ), African Journal Online, Bioline International, Open-J-Gate and Pharmacy Abstracts
\end{abstract}

\section{INTRODUCTION}

Diabetes mellitus (DM) is associated with high blood glucose levels as a result of impairment of insulin production or insulin effect. It causes ocular damage as well as dysfunctions in the kidney, heart, blood vessels and nervous system. In severe cases, DM results in electrolyte complications and disorders in acid-base balance [1]. The incidence of DM is increasing year by year, and cardiovascular complications are the main causes of increased mortality and 
decreased quality of life in DM patients. In the development of DM cardiomyopathy, the body undergoes apoptosis through complex molecular mechanisms and signaling pathways, leading to severe and deleterious changes in myocardial structure which may degenerate to heart failure. Thus, an important strategy in the treatment of DM is to prevent and control its complications with cardiovascular diseases $[2,3]$.

Studies have shown that retinoid acid receptor (RAR) agonists inhibit cardiomyocyte hypertrophy by regulating certain cell signaling pathways, thereby mitigating cardiac hypertrophy. Retinoid X receptor (RXR), a member of the nuclear hormone receptor superfamily which includes $\alpha, \beta$ and $y$ subtypes, is involved in regulating cell differentiation, proliferation, and immune function. Studies have shown that RXRa has a unique role in the receptor family through its interaction with many other nuclear receptors [4]. It has been reported that the RXR-specific agonist, bexarotene, significantly inhibited STZ-induced atherosclerosis in apoE ${ }^{-/-}$mice [5].

This study was carried out to investigate the effect of bexarotene on the structure and function of DM rats, using various imaging methods so as to provide potential therapeutic targets for the prevention of DM complications.

\section{EXPERIMENTAL}

\section{Animals and grouping}

Eight-week-old SPF rats $(n=48)$ weighing $180 \pm$ $20 \mathrm{~g}$ were purchased from Beijing Vitallihua, and kept at $22 \pm 2{ }^{\circ} \mathrm{C}$ and $55 \pm 5 \%$ humidity in an environment with $12 \mathrm{~h}$ light/day. Drinking water and feed were liberally provided. Four groups of rats were used: normal control, DM, DM + low dose Bex (10 mg/kg/day), and DM+ Bex (20 $\mathrm{mg} / \mathrm{kg} /$ day) groups (12 rats/group). Rat model of DM was established by intraperitoneal injection of STZ at a dose of $12 \mathrm{mg} / \mathrm{ml}$ in citrate buffer. The control group was intraperitoneally injected an equivalent amount of citrate buffer in place of STZ. Bexarotene was dissolved in distilled water and administrated through gavage once daily for 8 weeks. Rats in the control group received distilled water in place of bexarotene once daily for 8 weeks. After successful modeling, 10 rats were randomly selected from each group for the study. All procedures employed received approval from the Experimental Animal Ethics Committee of our institution.

This research was approved by the Animal Ethical Committee of Internal Medicine-
Cardiovascular Department, Qingdao Municipal Hospital (approval no. 201811212), and was implemented in line with Principles of Laboratory Animal Care (revised NIH publication) [6].

\section{Reagents and instruments}

The instruments and reagents used, and their manufacturers and models (in brackets) were: ultra-clean workbench (BCM-1000, Suzhou); ultrasonic treatment instrument (H66025T, Wuxi); fluorescence inverted phase contrast microscope (IX-70, Japan Olympus); deionized water machine (Labconco Company), GEVIVID E9 ultrasound System (12S probe, frequency 4 $12 \mathrm{MHz})$; low temperature ultracentrifuge (AllergraTM 64R, Beckman, USA); $\mathrm{CO}_{2}$ cell incubator (Shellb, Germany), 6-well culture plate (Costar, USA). The others were streptozotocin (STZ) (USA, Sigma); biszarotin (Eisai); $\beta$-actin monoclonal antibody (Abcam); Bcl2, Bax rabbit anti-rat primary antibody, acrylamide and TrisBase (USA, Sigma); HRP-labeled goat antisecondary antibody (Beijing Zhongshan Jinqiao Company); immunoblot chemiluminescence reagent (Santa Cruz), and blood glucose meter (Bayer, Germany).

\section{Animal studies}

Blood glucose level in the fasted state was determined using glucose oxidase. Whole heart and left ventricle masses were determined gravimetrically. Serum creatinine level was determined with picric acid method, while liver function was determined enzymatically. Cardiac structure and function were evaluated through echocardiography, using the parameters of aortic sinus diameter (systolic phase), left atrial anteroposterior diameter (systolic phase), interventricular septum diastole (IVSd), left ventricular posterior wall diastolic (LVPWd), left ventricular EF and FS. Changes in myocardial tissue structure were determined histologically with $\mathrm{H}$ \& $\mathrm{E}$ staining, while western blotting was used to assay the protein expressions of $\mathrm{Bcl} 2$ and Bax in rat myocardial tissue.

\section{Statistical analysis}

Data are presented as mean \pm SD. Multicomponent comparison was performed using one-way analysis of variance (ANOVA), while least significant difference (LSD) method was used for comparison between two groups. Statistical analysis was performed using SPSS19.0 software package. Values of $p<0.05$ were considered statistically significant. 


\section{RESULTS}

\section{Influence of bexarotene on blood glucose in} STZ-induced DM rats

As shown in Table 1, before treatment with bexarotene, the fasting blood glucose level of DM group was higher than that of normal control group $(p<0.05)$. There were no significant changes in blood glucose levels in the DM and $\mathrm{DM}+$ Bex (10 mg/kg/day) treatment groups at 2, 4 , and 8 weeks, when compared with their corresponding values before treatment $(p>$ 0.05). However, in the DM+ Bex (20 mg/kg/day) treatment group, blood glucose levels at 4 and 8 weeks after drug administration were significantly lower than the blood glucose level before treatment $(p<0.05)$.

\section{Influence of bexarotene on liver and kidney functions, and heart weight}

Table 2 shows that rats in the DM group had lower body weight, lower weight of left ventricular tissue, and lower heart weight than normal control rats $(p<0.05)$. Rat weight, and heart and left ventricular weights in the DM + Bex (20 $\mathrm{mg} / \mathrm{kg} /$ day) treatment group of rats were markedly increased, relative to DM group rats ( $p$ $<0.05)$. However, liver function and serum creatinine levels were comparable between diabetic rats in the two Bex treatment groups, and normal control rats $(p>0.05)$.

\section{Effect of bexarotene on various indicators of cardiac structure and function}

Table 3 shows that relative to control group, no appreciable differences were seen in AO (aortic root), left atrium, LVEDs, LVEDd, LVEF and LVFS in the DM group, DM + Bex (10 mg/kg/day) treatment group, and $\mathrm{DM}+\operatorname{Bex}(20 \mathrm{mg} / \mathrm{kg} / \mathrm{day})$ treatment group $(p>0.05)$. Moreover, AO, LA, LVEDs and LVFS were comparable among the three treatment groups $(p>0.05)$. In contrast, IVSd and LVPWd in DM rats were significantly decreased, relative to control values, while IVSd and LVPWd levels in rats treated with DM+Bex (20 $\mathrm{mg} / \mathrm{kg} /$ day) were significantly increased, relative to DM rats $(p>0.05)$.

Table 1: Influence of bexarotene on fasting blood glucose level in STZ-induced DM rats $(n=10)$

\begin{tabular}{lcccc}
\hline Group & Before treatment & 2 weeks & 4 weeks & 8weeks \\
\hline Normal control & $5.99 \pm 0.49$ & $5.87 \pm 0.56$ & $5.92 \pm 2.27$ & $6.17 \pm 2.70$ \\
DM & $25.63 \pm 3.74^{*}$ & $27.50 \pm 1.46^{*}$ & $25.16 \pm 3.06^{*}$ & $26.20 \pm 5.97^{*}$ \\
DM + Bex (10mg/kg/day) & $23.57 \pm 4.33$ & $27.88 \pm 2.34$ & $26.38 \pm 3.66$ & $24.96 \pm 5.13$ \\
DM + Bex (20 mg/kg/day) & $24.45 \pm 2.87$ & $24.44 \pm 2.88$ & $19.65 \pm 1.97^{\#}$ & $19.46 \pm 4.93^{\#}$ \\
\hline${ }^{*} P<0.05$, versus normal control ${ }^{\#} p<0.05$ vi
\end{tabular}

${ }^{\star} P<0.05$, versus normal control ${ }^{\#} p<0.05$, versus the same group before treatment

Table 2: Effect of bexarotene on cardiac weight and liver and kidney function

\begin{tabular}{|c|c|c|c|c|}
\hline Parameter & $\begin{array}{c}\text { Normal control } \\
\text { group }\end{array}$ & DM group & $\begin{array}{c}\text { DM+Bex } \\
(10 \mathrm{mg} / \mathrm{kg} / \mathrm{day})\end{array}$ & $\begin{array}{c}\text { DM+Bex } \\
(20 \mathrm{mg} / \mathrm{kg} / \text { day })\end{array}$ \\
\hline Body weight (g) & $367.51 \pm 7.52$ & $238.54 \pm 12.77$ & $253.13 \pm 17.26 \Delta$ & $352.81 \pm 26.37^{\#}$ \\
\hline Heart weight (g) & $1.10 \pm 0.11$ & $0.82 \pm 0.17^{\star}$ & $0.93 \pm 0.20$ & $1.10 \pm 0.13^{\Delta}$ \\
\hline $\begin{array}{l}\text { Weigth of left } \\
\text { ventricule }(\mathrm{g})\end{array}$ & $0.79 \pm 0.08$ & $0.61 \pm 0.08^{*}$ & $0.68 \pm 0.060$ & $0.85 \pm 0.13 \Delta^{\#}$ \\
\hline $\operatorname{ALT}(\mathrm{U} / \mathrm{L})$ & $9.84 \pm 3.57$ & $9.76 \pm 2.95$ & $9.90 \pm 3.27$ & $10.21 \pm 2.15$ \\
\hline AST (U/L) & $25.43 \pm 4.60$ & $24.45 \pm 4.30$ & $26.42 \pm 3.56$ & $27.45 \pm 4.20$ \\
\hline $\mathrm{BUN}(\mathrm{mmol} / \mathrm{L})$ & $1.75 \pm 0.60$ & $1.84 \pm 0.37$ & $1.95 \pm 0.30$ & $1.97 \pm 0.36$ \\
\hline $\mathrm{SCr}(\mathrm{mmol} / \mathrm{L})$ & $2.75 \pm 0.60$ & $2.85 \pm 0.99$ & $2.83 \pm 0.87$ & $2.94 \pm 0.19$ \\
\hline
\end{tabular}

Table 3: Ultrasound changes in heart tissue in DM rats (mean \pm SD)

\begin{tabular}{lllll}
\hline Index & $\begin{array}{l}\text { Normal control } \\
\text { group }\end{array}$ & DM group & $\begin{array}{l}\text { DM + low dose } \\
\text { Bex }\end{array}$ & $\begin{array}{l}\text { DM + high dose } \\
\text { Bex }\end{array}$ \\
\hline AO $(\mathrm{mm})$ & $3.97 \pm 0.21$ & $3.77 \pm 0.23$ & $4.11 \pm 0.38$ & $4.22 \pm 0.81$ \\
LA $(\mathrm{mm})$ & $4.62 \pm 0.55$ & $4.60 \pm 0.42$ & $4.84 \pm 0.83$ & $4.57 \pm 0.77$ \\
IVSd $(\mathrm{mm})$ & $1.67 \pm 0.08$ & $1.33 \pm 0.17^{*}$ & $1.41 \pm 0.22$ & $1.54 \pm 0.18^{\#}$ \\
LVPWd $(\mathrm{mm})$ & $1.68 \pm 0.15$ & $1.26 \pm 0.20^{*}$ & $1.38 \pm 0.22$ & $1.48 \pm 0.17^{\#}$ \\
LVEDd $(\mathrm{mm})$ & $7.28 \pm 0.25$ & $7.17 \pm 0.44$ & $7.41 \pm 0.49$ & $6.96 \pm 0.37$ \\
LVEDs $(\mathrm{mm})$ & $4.45 \pm 0.33$ & $4.36 \pm 0.35$ & $4.28 \pm 0.32$ & $4.17 \pm 0.33$ \\
LVEF $(\%)$ & $75.96 \pm 2.65$ & $71.67 \pm 3.14$ & $76.73 \pm 3.01$ & $75.84 \pm 2.45$ \\
LVFS $(\%)$ & $39.90 \pm 2.37$ & $36.22 \pm 2.53$ & $40.60 \pm 2.59$ & $39.91 \pm 1.90$ \\
\hline
\end{tabular}

${ }^{*} P>0.05$, versus normal control; ${ }^{\#} p>0.05$, versus DM group 


\section{Effect of bexarotene on myocardial structure of STZ-induced DM rats}

The results showed that cardiomyocytes from normal rats were arranged neatly, with uniform size of the nucleus and clear structural boundaries and clear horizontal stripes (Figure 1 A). In contrast, the myocardial cells from the DM group were irregularly arranged; the cell sizes were uneven, with blurred structural boundaries and unclear horizontal stripes (Figure $1 \mathrm{~B}$ ). In the $\mathrm{DM}+\operatorname{Bex}(10 \mathrm{mg} / \mathrm{kg} /$ day) treatment group, a more regular arrangement of cardiomyocytes, uniform cell size, and clear horizontal stripes were evident (Figure $1 \mathrm{C}$ ), while the $\mathrm{DM}+\mathrm{Bex}$ (20 $\mathrm{mg} / \mathrm{kg} /$ day) treatment group manifested regular arrangement of cardiomyocytes, uniform size of cell nucleus, and clear structural boundaries and horizontal stripes (Figure $1 \mathrm{D}$ ).

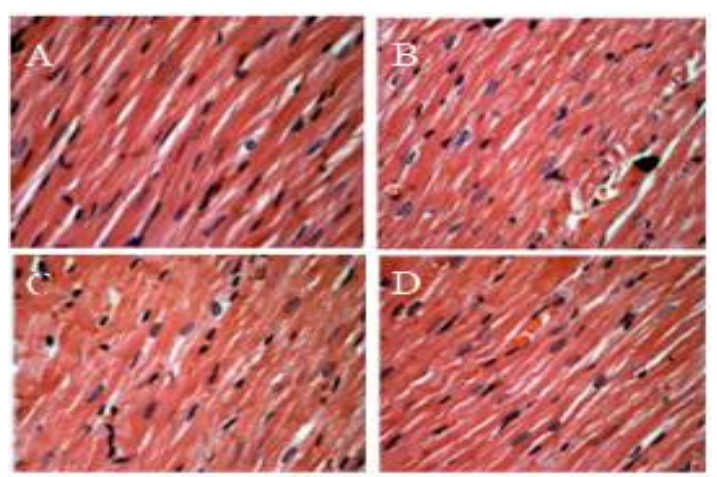

Figure 1: Influence of bexarotene on myocardial structure in STZ-induced DM rats. A: normal control group; B: DM group; C: DM+ low dose Bex treatment group; D: DM+ high dose Bex treatment group

Effects of bexarotene on the levels of apoptosis-related proteins ( $\mathrm{Bcl} 2$ and $\mathrm{Bax}$ ) in cardiomyocytes of DM rats
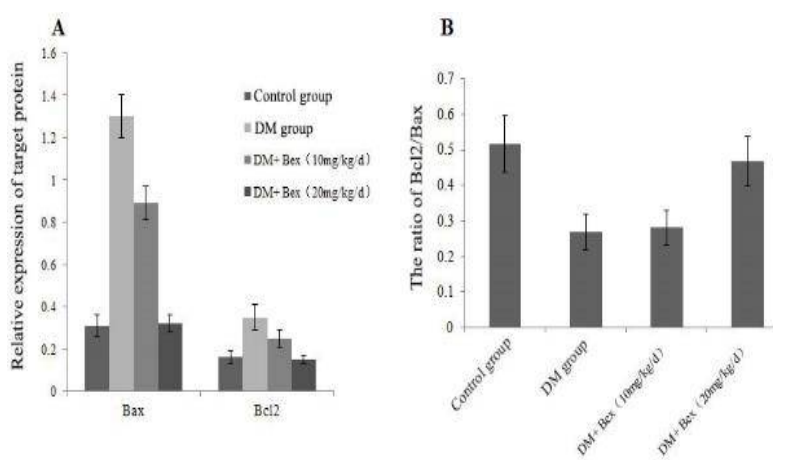

Figure 2: Effect of bexarotene on protein expressions of $\mathrm{Bcl} 2$ and Bax in STZ-induced rat cardiomyocytes

Figures $2 \mathrm{~A}$ and $\mathrm{B}$ show that the expression levels of $\mathrm{Bax}$ and $\mathrm{Bcl} 2$ in diabetic rats were markedly increased, when compared with normal rats, and the $\mathrm{Bcl} 2 / \mathrm{Bax}$ ratio was significantly lower $(p<0.05)$. The levels of Bcl2 and Bax in $\mathrm{DM}+$ high dose Bex treatment rats were markedly less than the corresponding levels in $\mathrm{DM}$ rats, and $\mathrm{Bcl} 2 / \mathrm{Bax}$ ratio was significantly elevated $(p<0.05)$.

\section{DISCUSSION}

Diabetes mellitus (DM) is a disease caused by chronic, persistent hyperglycemia due to absolute or relative lack of insulin secretion. Epidemiological investigations have shown that the incidence of cardiovascular disease in DM patients is 2 to 3 times higher than that in nonDM patients. Diabetes mellitus (DM) is one of the major risk factors for heart failure [7]. Chronic hyperglycemia is the most important factor for the microvascular and cardiovascular complications of DM. Hyperglycemia affects the structure and function of cardiomyocytes through various signal transduction systems, leading to cardiac insufficiency [8]. Echocardiography is usually used in the clinical evaluation of myocardial structure and function in DM patients. However, due to its low sensitivity, echocardiography is not able to evaluate early alterations in myocardial structure and function in diabetic patients. Studies have shown that RXRa inhibits cell proliferation, delays cell growth, and inhibits cell protein synthesis through multiple pathways [9]. In the present study, the RXRa agonist bexarotene was used to treat STZinduced DM rats, and its mechanism of inhibiting ventricular remodeling and cardiomyocyte apoptosis was further explored, resulting in good results.

Disorders in peripheral and cardiac glycolipid metabolism constitute the major causative factors associated with impairments in structure and function in DM. Studies have shown that hyperglycemia increases the expression of advanced glycation end-products and their receptors; activates nuclear transcription factors, alters myocardial contractility, changes structural proteins, increases myocardial stiffness, and induces myocardial interstitial fibrosis $[10,11]$. Left ventricular hypertrophy is a pathological change in most heart diseases and an important risk factor for many cardiovascular diseases. There are significant changes in cardiac structure at the early stages of DM, but as the disease progresses, there is a gradual enlargement of the left atrium and left ventricle [12].

In this study, conventional echocardiography was employed for determination of lesions in myocardial morphology and function in DM rats 
and the effect of bexarotene on DM cardiomyopathy. The results showed that the fasting blood glucose level was higher in diabetic rats than in normal rats. Blood glucose levels at the 4th and 8th weeks after treatment in the DM + Bex (20 mg/kg/day) treatment group were significantly lower than that before treatment. Rat weight, whole heart weight and left ventricular weight of DM group were significantly lower than those of the control group.

Levels of IVSd and LVPWd in the DM group were markedly reduced, relative to control, and IVSd and LVPWd levels in the DM + Bex (20 $\mathrm{mg} / \mathrm{kg} /$ day) treatment group were significantly increased, relative to DM group. These results suggest that left ventricular weight loss is one of the important features of DM cardiomyopathy, and that bexarotene not only restored the left ventricular weight, but also improved cardiac systolic function in DM cardiomyopathy rats. The different doses of bexarotene used in the study did not produce significant hepato-renal toxicity, indicating the safety of the treatment at low doses. The results from histology also confirmed changes in myocardial structure in DM cardiomyopathy, as manifested in the disordered cell arrangement, uneven cell size, and blurring of structural boundary and horizontal grain. Moreover, the results of this study showed that bexarotene mitigated myocardial remodeling in DM rats. This may be an important mechanism for the improvement of cardiac structure and function in DM rats. The anti-oxidative stress, anti-inflammatory and anti-proliferative effects of bexarotene may be responsible for its mitigation of cardiac remodeling [13].

Apoptosis of cardiomyocytes is one of the important mechanisms involved in myocardial ischemia-reperfusion injury in DM. The $\mathrm{Bcl} 2$ and Bax are important factors that regulate the mitochondrial apoptosis pathway. The $\mathrm{Bcl} 2$ protein is a membrane-bound protein located in mitochondria and lysosomes. Being an antiapoptotic protein, it plays an important role in the regulation of apoptosis [14]. The function of Bax gene is opposite to that of Bcl2 gene; Bax forms heterodimers which inactivate $\mathrm{Bcl} 2$ protein, thus promoting cell apoptosis. During myocardial ischemia and ischemia-reperfusion, $\mathrm{Bcl} 2$ protein expression is significantly down-regulated, while and Bax gene expression is significantly upregulated, suggesting that $\mathrm{Bcl} 2$ and $\mathrm{Bax}$ are involved in the regulation of apoptosis in myocardial ischemia-reperfusion injury $[15,16]$.

The results of this study indicate that bexarotene significantly down-regulated the expressions of Bcl2 and Bax proteins, inhibited cardiomyocyte apoptosis, and up-regulated the relative ratio of $\mathrm{Bcl}$ /Bax, suggesting that inhibition of cardiomyocyte apoptosis may be a mechanism involved in the bexarotene-induced improvement of cardiac structure and function in a rat model of STZ-induced DM.

\section{CONCLUSION}

Changes in left ventricular structure and function in diabetic cardiomyopathy occur earlier than changes in EF and FS values. Bexarotene significantly mitigates impairments in heart structure and function in diabetic rats via a mechanism related to reduction in blood glucose, inhibition of ventricular remodeling, and suppression of apoptosis of cardiomyocytes. These findings may be beneficial in the development of new anti-DM drugs.

\section{DECLARATIONS}

\section{Conflict of interest}

No conflict of interest is associated with this work.

\section{Contribution of authors}

We declare that this work was done by the author(s) named in this article and all liabilities pertaining to claims relating to the content of this article will be borne by the authors all authors read and approved the manuscript for publication. Guo Xi conceived and designed the study, Ying Ma, Yunfeng Li, Yongqiang Ren, Guo $\mathrm{Xi}$ collected and analysed the data while Ying $\mathrm{Ma}$ wrote the manuscript.

\section{Open Access}

This is an Open Access article that uses a funding model which does not charge readers or their institutions for access and distributed under the terms of the Creative Commons Attribution License (http://creativecommons.org/licenses/by/ 4.0) and the Budapest Open Access Initiative (http://www.budapestopenaccessinitiative.org/rea d), which permit unrestricted use, distribution, and reproduction in any medium, provided the original work is properly credited.

\section{REFERENCES}

1. Switzer NJ, Prasad S, Debru E, Church N, Mitchell P, Gill RS. Sleeve Gastrectomy and Type 2 Diabetes Mellitus: a Systematic Review of Long-Term Outcomes. Obes Surg 2016; 26(7): 1616-1621. 
2. Giugliano D, Ceriello A, Paolisso G. Diabetes mellitus, hypertension, and cardiovascular disease: which role for oxidative stress? Metabolism Clin Exp 2016; 44(3): 360368.

3. Zhao H, Feng JH, Wu XP. Progress in the pathogenesis of diabetic cardiomyopathy. Int J Cardiovas Dis 2016; 43(1): 16-18.

4. Xie $Y$, Zhou $X Y$, Hao HP, Wang GJ. Progress in the role of farnesoid $X$ receptor in metabolic regulation and tumor cell proliferation. Sheng Li Xue Bao 2014; 66(2): 252-258.

5. Wang J, Xu P, Xie X, Li J, Zhang J, Wang J, Hong F, Li J, Zhang $Y$, Song $Y$, et al. DBZ (Danshensu Bingpian Zhi), a Novel Natural Compound Derivative, Attenuates Atherosclerosis in Apolipoprotein E-Deficient Mice. J Am Heart Assoc 2017; 6(10): 006297.

6. World Health Organization. Principles of laboratory animal care. WHO Chron 1985; 39: 51-56.

7. Fox CS, Golden SH, Anderson C, Bray GA, Burke LE, de Boer IH, Deedwania P, Eckel RH, Ershow AG, Fradkin $J$, et al. Update on Prevention of Cardiovascular Disease in Adults with Type 2 Diabetes Mellitus in Light of Recent Evidence: A Scientific Statement From the American Heart Association and the American Diabetes Association. Diabetes Care 2015; 38(9): 1777-1803.

8. Ceriello $A$. The post-prandial state and cardiovascular disease: relevance to diabetes mellitus. Diabetes Metab Res Rev 2015; 16(2): 125-132.

9. Wei $X, X u Y$, Jin $Y$, Feng $H$, Xiao $Y$, Dong S. Granulocyte colony-stimulating factor attenuates blood-brain barrier damage and improves cognitive function in spontaneously hypertensive rats. CNS Neurol Disord Drug Targets 2017; 16(7): 781-788.
10. Liu $X Y$, Liu FC, Deng CY, Zhang MZ, Yang $M$, Xiao DZ, Lin QX, Cai ST, Kuang SJ, Chen J, et al. Left ventricular deformation associated with cardiomyocyte $\mathrm{Ca}^{2+}$ transients delay in early stage of low-dose of STZ and high-fat diet induced type 2 diabetic rats. BMC Cardiovasc Disord 2016; 16(1): 41.

11. Shi Wei, Liu Haixia, Luo Yi, Wang YS, Liu SJ. Clinical study of echocardiographic evaluation of fetal heart structure and function in pregnant women with gestational diabetes. Advances Mod Biomed 2017; 17(12): 2338-2341.

12. Walker AM, Patel PA, Rajwani A, Groves $D$, Denby $C$, Kearney L, Sapsford RJ, Witte KK, Kearney MT, Cubbon RM. Diabetes mellitus is associated with adverse structural and functional cardiac remodelling in chronic heart failure with reduced ejection fraction. Diab Vasc Dis Res 2016; 13(5): 331.

13. Chai Dajun, Xu Junxia, Xu Changsheng, Zhu J, Lin JX. Retinol $X$-receptor agonists inhibit TGF- $\beta 1$-induced collagen synthesis in cardiac fibroblasts by regulating Smad2 pathway. Chin J Pathophysiol 2016; 32(12): 2228-2232.

14. Liang JJ, Wang $F$, Shi $S B$, Shen $Y Y$, Yuan XR, Huang $H$, Yang B. Changes and significance of $\mathrm{Bax} / \mathrm{BCl}-2$ in cardiomyocytes of rats with post-myocardial depression. J Clin Int Med 2015; 32(6): 417-420.

15. Borujeni MJS, Hami J, Haghir H, Rastin M, Sazegar G. Evaluation of Bax and Bcl-2 Proteins Expression in the Rat Hippocampus due to Childhood Febrile Seizure. Iranian J Child Neurol 2016; 10(1): 53-60.

16. Fang JH, Yang W. Research progress of Bcl-2 family proteins on cardiomyocyte apoptosis. Mod Med 2017; (7): 996-1000. 